Check for updates

Cite this: RSC Adv., 2018, 8, 3392

\title{
Mechanism of byproducts formation in the isobutane/butene alkylation on HY zeolites
}

\author{
Zhiwei Chen, ${ }^{a}$ Feng Gao, ${ }^{a}$ Kun Ren, ${ }^{a}$ Quangui Wu, ${ }^{\mathrm{b}}$ Yan Luo, ${ }^{\mathrm{c}}$ Hongjun Zhou, ${ }^{a}$ \\ Meng Zhang ${ }^{d}$ and Quan Xu (D)*a
}

Submicron-size HY zeolites with a particles size of 200-700 nm were synthesized employing a crystal precipitation method in this study. The catalytic activity for the isobutane/butene alkylation was evaluated. The results indicated that butene conversion was above $90 \%$ and the selectivity of expected products (C8) was nearly at $90 \%$ within 72 h. The micropores-blocking and coverage of acid sites resulting from high hydrocarbons increased the difficulty for the diffusion of products to the bulk and inhibited the adsorption of reactant on activity sites, which caused deactivation of catalyst. The ultimate C12 content in alkylate oil, stemmed from trimerization of butene, was reduced via the addition reaction with butene to $\mathrm{C} 16$ and the cracking to C5-C7. The formation mechanisms and transformation processes of byproducts in alkylate oil revealed that the source of C9-C11 switched from cracking of $\mathrm{C} 16+$ to the addition of $\mathrm{C} 5-\mathrm{C} 7$ carbocations with butene when acid sites concentration was reduced by accumulating oligomers.

Received 21st November 2017 Accepted 14th December 2017

DOI: 10.1039/c7ra12629h

rsc.li/rsc-advances investigating new solid acid catalysts (super solid acid, heteropolyacid and zeolites) and decreasing the critical reaction conditions. ${ }^{2}$ However, there are numerous limitations at an industrial scale, ascribed to fast deactivation caused by oligomerization of butene. Thus, solid acid catalysts for alkylation, particularly zeolites, are a promising research field due to outstanding advantages in environment protection.

Among the zeolites used in isobutane/butene alkylation, which include $\mathrm{Y}^{3-8} \mathrm{X},{ }^{9-11} \quad \beta,{ }^{12-15}$ mordenite, ${ }^{13,16} \mathrm{ZSM}^{17}$ and $\mathrm{MCM}^{18}{ }^{18}$ the $\mathrm{Y}$ zeolites are the most studied because of their considerable activity for hydride transfer and large pore size. ${ }^{19}$ However, the controversy regarding the activity of the protonic form of $\mathrm{Y}$ zeolites towards alkylation has raged unabated. Querinl et $a l^{20}$ reported that HY was not active for TMP formation due to a strong adsorption of the olefins and subsequent oligomerization as a consequence of very fast deactivation. Corma et al. ${ }^{18}$ investigated the impact of the unit cell size of steam-dealuminated Y zeolites and found that oligomerization continuously increased with the zeolite unit cell size although the maximum conversion of 2-butene was attained on samples with unit cell sizes between 2.435 and $2.450 \mathrm{~nm}$. Although strong Brønsted acid sites that benefit alkylation can be achieved by ion-exchange with $\mathrm{La}^{3+}$, the alkylation efficiency on LaY was not satisfactory because of the short lifespan of the zeolite and low selectivity to isooctane. ${ }^{4}$ Hence, it is necessary to further study Y zeolites.

It is known that $\mathrm{C} 8$ hydrocarbons are the main products in C5+ alkylate over all types of zeolites and the distribution of individual components depends on the catalyst categories and reaction conditions. In order to increase the selectivity of 
desirable alkylate trimethylpentane (TMP), considerable research has been carried out to understand the formation mechanism of $\mathrm{C}^{2} .^{21-24}$ However, the formation pathways of the byproducts were discussed roughly. It is expected that the C5C7 hydrocarbon species are derived from the cracking of higher hydrocarbons by $\beta$-scission, and the $\mathrm{C} 9+$ hydrocarbon species are formed via butene oligomerization. However, the interesting phenomenon that the main byproduct of $\mathrm{C} 9+$ over solid acid catalysts is a C11 chain hydrocarbon rather than C12 has not been explained. The group ${ }^{25}$ also found that a coke precursor deposited on the surface of zeolites was comprised of long chain alkanes in which the number of carbon atoms was odd.

The objective of this study is to demonstrate that HY zeolites exhibit activity for isobutene/butene alkylation and reveal the formation mechanism of the main alkylation byproducts over HY zeolites.

\section{Experimental section}

\subsection{Synthesis of HY zeolites}

Sodium metasilicate, sodium aluminate, and sodium hydroxide were dissolved in deionized water according to the mole ratio $16 \mathrm{Na}_{2} \mathrm{O}: \mathrm{Al}_{2} \mathrm{O}_{3}: 15 \mathrm{SiO}_{2}: 300 \mathrm{H}_{2} \mathrm{O}$. Subsequently, the mixture was aged at room temperature for $12 \mathrm{~h}$ to generate a crystallization directing agent. Then, the above mixture and directing agent were transferred into an autoclave and crystallized at $100{ }^{\circ} \mathrm{C}$ for $12 \mathrm{~h}$ according to the mole ratio of $2.7 \mathrm{Na}_{2} \mathrm{O}: \mathrm{Al}_{2} \mathrm{O}_{3}: 8.4 \mathrm{SiO}_{2}: 200 \mathrm{H}_{2} \mathrm{O}$. It is worth noting that Si derived from the guiding agent would not be lower than $90 \%$. The obtained solution mixture was filtered through vacuum suction filtration and washed with deionized water. The resultant solid was dried at $120{ }^{\circ} \mathrm{C}$ overnight and calcined at $550{ }^{\circ} \mathrm{C}$ for $4 \mathrm{~h}$ to form the parent powder of NaY. HY zeolite powder was obtained by the ion-exchange between $\mathrm{NaY}$ powder and $1 \mathrm{~mol} \mathrm{~L}^{-1} \mathrm{NH}_{4} \mathrm{Cl}$ aqueous solution, drying, and stepwise calcination. The above steps were repeated thrice. The final catalysts were prepared through a series of steps, including extrusion with a binder into cylindrical shape, drying at $120^{\circ} \mathrm{C}$ for $12 \mathrm{~h}$, and calcination at $350^{\circ} \mathrm{C}$ for $2 \mathrm{~h}$ and then at $550^{\circ} \mathrm{C}$ for $3 \mathrm{~h}$.

\subsection{Characterization}

X-Ray Powder Diffraction (XRD) spectra of the catalysts were recorded using a D8 Advance (Bruker, Germany) diffractometer operating at $40 \mathrm{~mA}$ and $40 \mathrm{kV}$ using monochromated $\mathrm{Cu} \mathrm{K} \alpha_{1}$ radiation $(\lambda=1.541 \AA)$ in the $2 \theta$ range from $5^{\circ}$ to $90^{\circ}$. The diffraction data was recorded using continuous scanning at a rate of $0.02^{\circ} \mathrm{s}^{-1}$. Scanning electron microscopy (SEM) images were collected on a ZEISS Gemini SEM300 at $5 \mathrm{kV}$. Powder samples extruded mouldings for SEM imaging were placed on a conductive adhesive. $\mathrm{N}_{2}$ adsorption-desorption studies were conducted at $-196^{\circ} \mathrm{C}$ after sample pretreatment under vacuum at $250{ }^{\circ} \mathrm{C}$ for $4 \mathrm{~h}$. The specific surface area was determined by the Brunauer-Emmett-Teller (BET) method in the $P / P_{0}$ range $0.05-0.2$, and the pore size distribution was calculated by the Barrett-Joyner-Halenda (BJH) method using the desorption branch of the isotherm. Brønsted and Lewis acid concentrations were obtained from pyridine-IR spectra. Before measurement, the samples were pressed into self-supporting wafers and dried under vacuum at $400{ }^{\circ} \mathrm{C}$ for $1 \mathrm{~h}$ to remove water and weakly adsorbed deposits. Then, pyridine was adsorbed at $30^{\circ} \mathrm{C}$ in vacuum for $2 \mathrm{~h}$ until no changes were observed in the spectrum. After weakly physisorbed pyridine was removed, the IR spectra were recorded at $200{ }^{\circ} \mathrm{C}$.

\subsection{Isobutane/butene alkylation test}

Initially, $5 \mathrm{~g}$ fresh $\mathrm{HY}$ zeolite was loaded in the constant temperature section of a stainless tubular reactor with inner diameter of $12 \mathrm{~mm}$ and length of $50 \mathrm{~cm}$. Prior to reaction, the catalysts were pretreated at $500{ }^{\circ} \mathrm{C}$ for $1 \mathrm{~h}$ in $\mathrm{N}_{2}$ at a flow rate of $40 \mathrm{~mL} \mathrm{~min}^{-1}$ in order to remove the water adsorbed over the zeolites. Then, the reactor was cooled by $\mathrm{N}_{2}$ to the reaction temperature and pressurized to 2.0 MPa. Finally, the isobutane/ butene mixture with a molar ratio of $\mathrm{I} / \mathrm{O}=180$ was pumped (SZWEICO, 2ZB-1L10A) to the reactor at a weight hourly space velocity (WHSV) of $7.5 \mathrm{~h}^{-1}$. The mixture of butenes consisted of 1-butene, 2-butenes, and isobutene at concentrations of 16.3, 83.1, and $0.6 \mathrm{wt} \%$, respectively. The reaction was stopped when the conversion rate of butene was lower than $90 \%$ or time on stream (TOS) reached $72 \mathrm{~h}$.

The components in the liquid-phase product were analyzed using a gas chromatograph GC-9720/FID with a capillary column $(50 \mathrm{~m} \times 0.2 \mathrm{~mm} \times 0.5 \mu \mathrm{m}$ Agilent-HP-PONA). The GC9790II/FID with a capillary column $(30 \mathrm{~m} \times 0.530 \mathrm{~mm}$ Agilent-GC-Alumina) was employed to determine the components of feedstock and effluent gas. The butene conversion and product selectivity could be calculated according to eqn (1) and (2).

$$
\begin{gathered}
\text { Butene conversion }(\%)=\frac{F_{\text {in }} y_{\text {in }}-F_{\text {out }} y_{\text {out }}}{F_{\text {in }} y_{\text {in }}} \times 100 \% \\
\text { Product selectivity }(\%)=\frac{y_{i}}{\sum_{i=5} y_{i}} \times 100 \%
\end{gathered}
$$

where $F_{\text {in }}, F_{\text {out }}$ and $y_{\text {in }}, y_{\text {out }}$ refer to the molar flow and butene percentage at the reactor inlet and outlet, respectively, and $y_{i}$ is the molar percent of product with $i$ number of carbons in the effluent.

\subsection{Regeneration of used catalyst}

The catalyst needed to be regenerated when the time on stream reached $72 \mathrm{~h}$ or the butene conversion decreased to $90 \%$. The used catalysts were regenerated in situ at a temperature of $450{ }^{\circ} \mathrm{C}$ at atmospheric pressure for $12 \mathrm{~h}$ by passing air at a flow rate of $50 \mathrm{~mL} \mathrm{~min}^{-1}$. Subsequently, the reaction bed was cooled to $75{ }^{\circ} \mathrm{C}$ by $\mathrm{N}_{2}$ at a rate of $40 \mathrm{~mL} \mathrm{~min}{ }^{-1}$ and then pressurized at 2.0 MPa. The alkylation reaction proceeded by purging feedstock at the same reaction conditions as fresh catalysts after the carbon deposit was wiped off.

\section{Results and discussion}

\subsection{Characterization of catalysts}

The powder XRD patterns of the synthesized and used catalysts (Fig. 1) exhibited characteristic peaks at $2 \theta=6.25^{\circ}, 10.19^{\circ}$, 


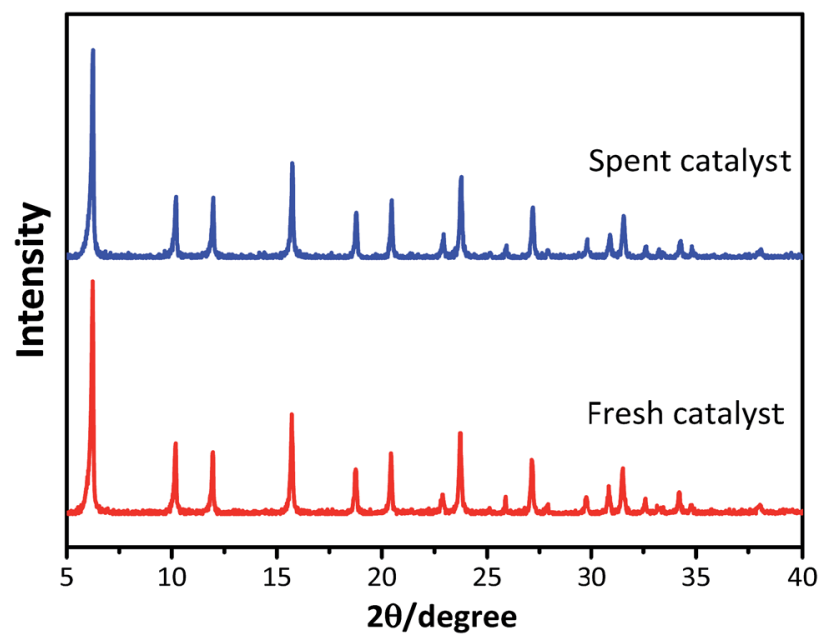

Fig. 1 XRD patterns of fresh and spent catalysts.

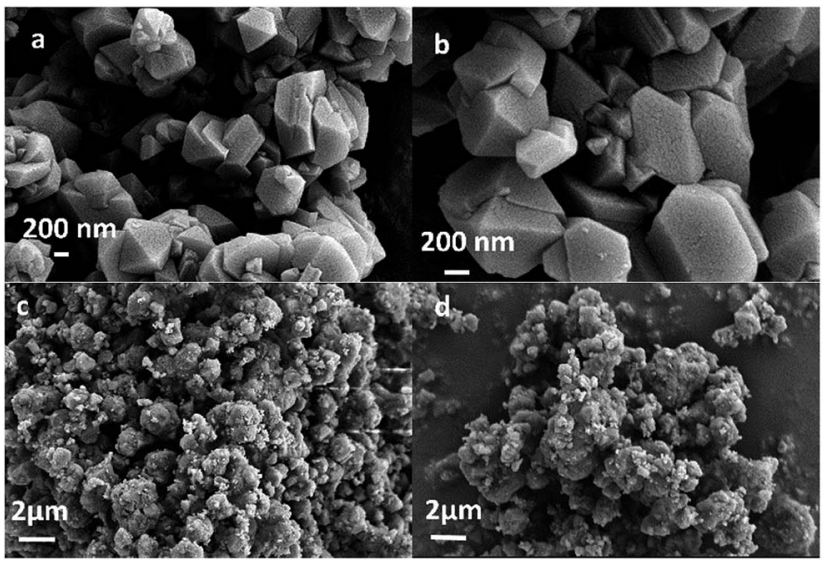

Fig. 2 SEM images (a and b) HY powder before extrusion; (c) fresh HY; and (d) spent HY. $11.96^{\circ}, 15.72^{\circ}, 18.76^{\circ}, 20.44^{\circ}$, and $23.73^{\circ}$, in accordance with the reference patterns for HY zeolites in the Joint Committee on Powder Diffraction Standards (JCPDS) database, indicating that the synthesized HY zeolites were well-crystallized and pure. The inferior peak intensities of the spent zeolites when compared to that of fresh catalyst were due to the carbon deposits on the catalysts.

Fig. 2 displays the SEM images of the synthesized HY zeolites with prominent crystal morphology. The particles sizes ranged from 200 to $700 \mathrm{~nm}$. However, visible agglomeration of the particles is observed and the entangled particles that are inserted in each other decrease the efficient surface for reaction. The agglomeration became more severe after deactivation (Fig. 2(d)) when compared to the fresh zeolites (Fig. 2(c)).

The $\mathrm{N}_{2}$ adsorption-desorption isotherms and pore size distributions of the fresh and used HY zeolites are depicted in Fig. 3(a) and (b). Both isotherms observed in Fig. 3(a) display type IV behavior with a hysteresis loop above $p / p_{0}=0.4$, which can be typically observed in mesoporous materials with pore diameter up to $c a .50 \mathrm{~nm}$. Moreover, a steep increase at $p / p_{0}<$ 0.02 of the catalysts can be interpreted as microporous filling, while the other steep increase at $0.4<p / p_{0}$ is caused by capillary condensation in the mesopores. The pore distribution has an insignificant change as observed in Fig. 3(b), where apparent mesopores with a specific diameter of $7.61 \mathrm{~nm}$ along with a narrow distribution are observed. In addition, the amount of pores with different sizes of catalysts decreased after the alkylation reaction. The reason for the above phenomenon could be that oligomers of olefins absorbed to the micro and mesopores cannot diffuse to the bulk phase. The concrete values of the textural properties of zeolites, including specific surface area and pore volume, are listed in Table 1. All the textural indictors of fresh catalysts declined after the alkylation reaction. In particular, the micropore specific surface area and micropore volume decrease by $18.8 \%$ and $19.1 \%$, respectively. This was possibly resulted from bulk pores and covered surface with oligomers. The catalysts began to deactivate when large
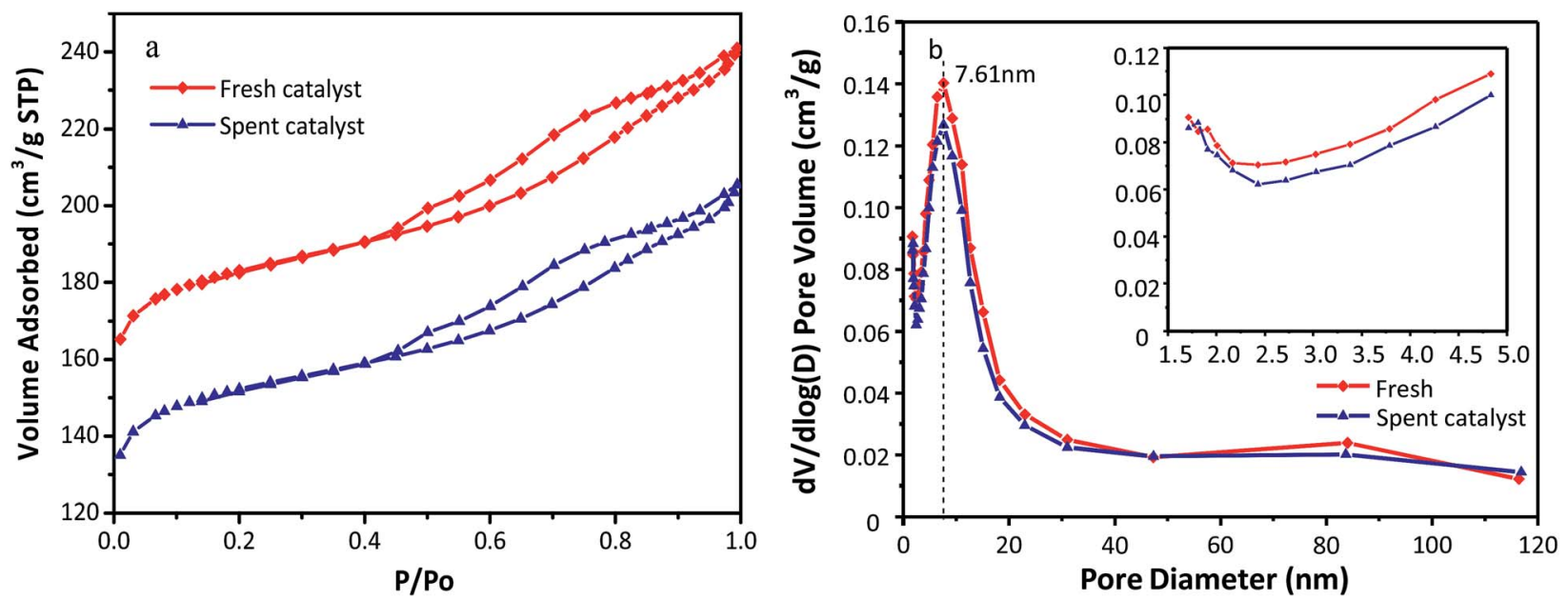

Fig. 3 (a) $\mathrm{N}_{2}$ adsorption-desorption isotherm and (b) pore sizes distribution of fresh and spent HY zeolites. 
Table 1 Textural properties of fresh and used HY zeolites

\begin{tabular}{llllll}
\hline $\begin{array}{l}\text { HY } \\
\text { catalyst }\end{array}$ & $\begin{array}{l}S_{\mathrm{BET}} \\
\left(\mathrm{m}^{2} \mathrm{~g}^{-1}\right)\end{array}$ & $\begin{array}{l}S_{\text {micro }}{ }^{a} \\
\left(\mathrm{~m}^{2} \mathrm{~g}^{-1}\right)\end{array}$ & $\begin{array}{l}V_{\mathrm{P}}{ }^{b} \\
\left(\mathrm{~cm}^{3} \mathrm{~g}^{-1}\right)\end{array}$ & $\begin{array}{l}V_{\text {micro }}{ }^{c} \\
\left(\mathrm{~cm}^{3} \mathrm{~g}^{-1}\right)\end{array}$ & $\begin{array}{l}V_{\text {meso }}{ }^{d} \\
\left(\mathrm{~cm}^{3} \mathrm{~g}^{-1}\right)\end{array}$ \\
\hline Fresh & 588.3 & 479.8 & 0.360 & 0.235 & 0.125 \\
Spent & 490.6 & 389.7 & 0.305 & 0.190 & 0.115
\end{tabular}

${ }^{a} S_{\text {micro }}=t$-plot micropore area. ${ }^{b} V_{\mathrm{p}}=$ total pore volume. ${ }^{c} V_{\text {micro }}=t$ plot micropore volume. ${ }^{d} V_{\text {meso }}=$ mesopore volume determined by BJH method.

hydrocarbons generated in the micropores fail to diffuse to bulk phase. ${ }^{9}$

Fig. 4 exhibits the Py-IR spectra to qualitatively and quantitatively determine the Lewis acid and Brønsted acid concentrations in $\mathrm{HY}$ zeolites located at $1545 \mathrm{~cm}^{-1}$ and $1455 \mathrm{~cm}^{-1}$, respectively. ${ }^{26-28}$ The surface Brønsted (B) and Lewis (L) acid sites concentrations were calculated according to the equation published by Emeis $^{29}$ and the results are summarized in Table 2. The Brønsted acid sites are dominant in both fresh and used HY zeolites, while the amount of Lewis acid sites is small. The amount of $\mathrm{B}$ and $\mathrm{L}$ acid types decreased by $19.7 \%$ and $3.4 \%$ after the alkylation reaction, respectively. The ratio of $\mathrm{B} / \mathrm{L}$ declined from 3.8 to 3.22 , demonstrating that Brønsted acid type was primarily responsible for alkylation and the decrease of Brønsted acid sites was the main reason for catalyst deactivation.

\subsection{Alkylation activity of the synthesized catalysts}

The activity of the synthesized HY zeolites for isobutane/butene alkylation was investigated. The butene conversions over time on stream at various temperatures $\left(70,75\right.$, and $\left.80^{\circ} \mathrm{C}\right)$ are shown in Fig. 5, where conversion gradually decreased from $100 \%$ in the initial $12 \mathrm{~h}$ to 91,92 , and $95 \%$ at the end of the reactions after $70 \mathrm{~h}$, respectively. The minimum decrease in butene conversion was achieved at a reaction temperature of $75^{\circ} \mathrm{C}$. The possible reason was that lower temperature was not beneficial

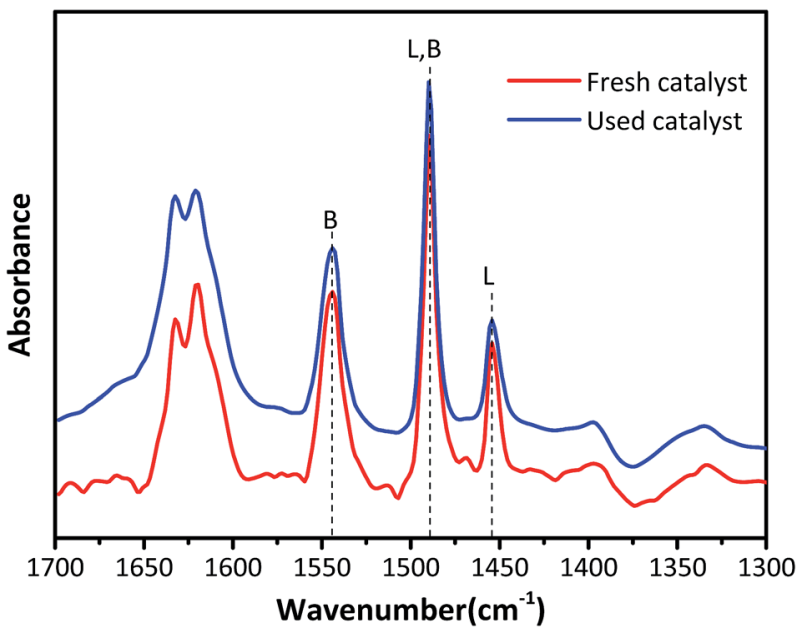

Fig. 4 Py-IR profiles at the desorption temperature of $200^{\circ} \mathrm{C}$.
Table 2 Brønsted and Lewis acid sites concentrations of the fresh and used HY zeolites

\begin{tabular}{llll}
\hline Catalyst & $C_{\mathrm{B}}\left(\mathrm{mmol} \mathrm{g}^{-1}\right)$ & $C_{\mathrm{L}}\left(\mathrm{mmol} \mathrm{g}^{-1}\right)$ & $\mathrm{B} / \mathrm{L}$ \\
\hline Fresh & 0.1019 & 0.0263 & 3.8 \\
Used & 0.0818 & 0.0254 & 3.22
\end{tabular}

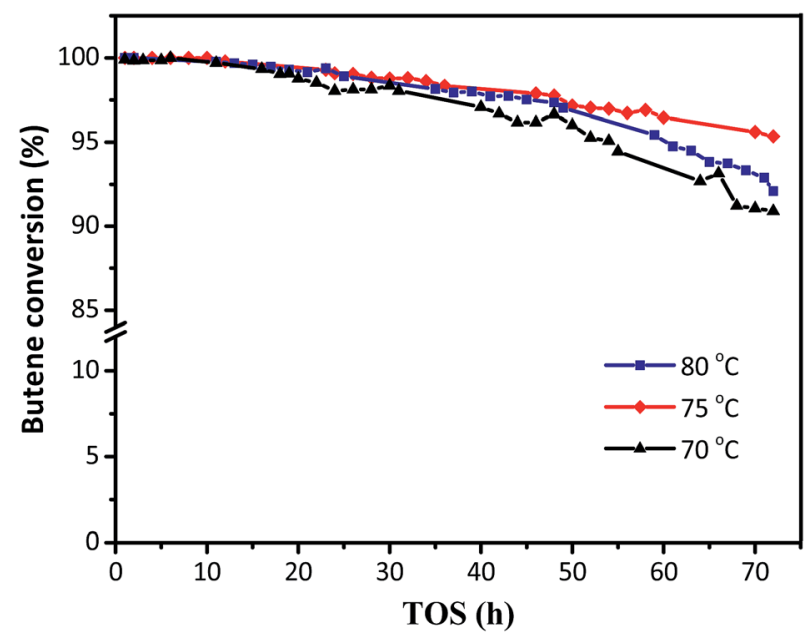

Fig. 5 The effects of reaction temperatures on butene conversion. Reaction condition: the ratio of isobutane to butene $(I / O=180), P=$ 2.0 $\mathrm{MPa}, \mathrm{WHSV}=7.5 \mathrm{~h}^{-1}$.

for the activation and diffusion of reactants and products as well as overcoming steric hindrance. However, higher temperature was more convenient for butene oligomerization resulting in a decline of activity centres. ${ }^{8}$ The covering surface and bulk pore values are summarized in Table 1 and Fig. 2, and the decrease of Brønsted acidities is illustrated in Fig. 4 and Table 2.

The distribution of individual components in the alkylate at the optimal temperature of $75{ }^{\circ} \mathrm{C}$ is shown in Fig. 6, revealing

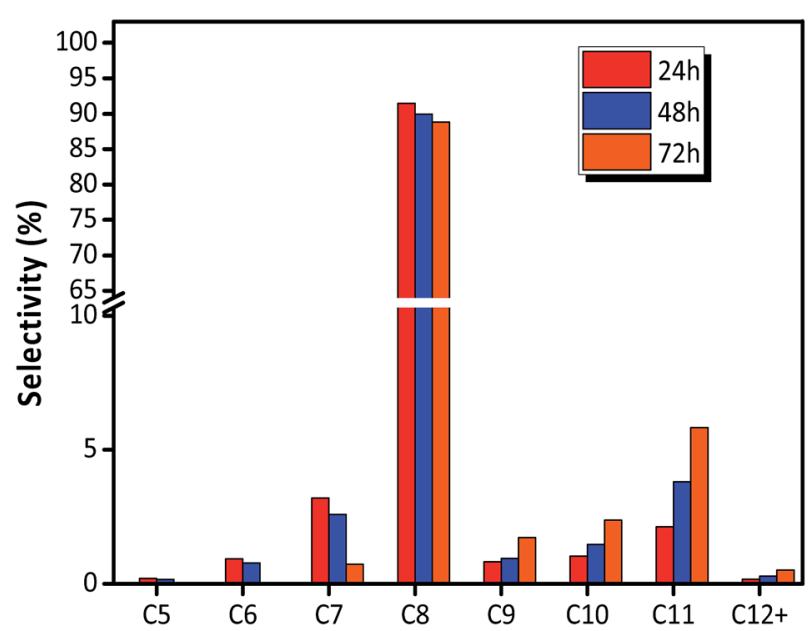

Fig. 6 Selectivity of each component in alkylate $(\mathrm{C} 5+)$ over $\mathrm{HY}$ zeolites. Reaction condition: the ratio of isobutane to butene $(\mathrm{I} / \mathrm{O}=$ 180), $P=2.0 \mathrm{MPa}, \mathrm{WHSV}=7.5 \mathrm{~h}^{-1}$. 
that the selectivity of $\mathrm{C} 5-\mathrm{C} 7$ and $\mathrm{C} 8$ decreased with TOS, but the selectivity of C9+ increased. The high selectivity of C8 hydrocarbon species (above 80\%) and the low selectivity of $\mathrm{C} 12+$ (lower than $1 \%$ at $72 \mathrm{~h}$ ), observed in Fig. 6, reflected that the synthesized HY zeolites had great stability and also, the oligomerization activity producing higher hydrocarbons (over C12) was limited in this stage due to a highly active catalyst. The selectivities of the main constituents of C8, namely, trimethylpentane, dimethylhexane $(\mathrm{DMH})$, and $\mathrm{C} 8=$ are described in Fig. 7. The selectivities of TMP and DMH were stable at 75 and $15 \%$, respectively, while the selectivity of $\mathrm{C} 8=$ was less than $1 \%$. In general, C5-C7 species were derived from oligomers, such as $\mathrm{C} 12+$, through cleavage of $\mathrm{C}-\mathrm{C}$ bonds, while $\mathrm{C} 9+$ species was generated from oligomerization of butene. ${ }^{23}$ Although both cracking and oligomerization require acid centers, the former took place on Brønsted acid centres and the latter primarily depended on Lewis acid centers. The paralleled selectivity tendencies of $\mathrm{C} 5-\mathrm{C} 7$ and $\mathrm{C} 8$ were in accordance with the requirement of the same Brønsted acid active sites for alkylation and cracking. ${ }^{30}$ In addition, the acidity strength needed by each reaction step in the process of alkylation was different: cracking > alkylation (electrophilic addition of butene to iso$\mathrm{C}_{4} \mathrm{H}_{9}{ }^{+}$) > oligomerization (electrophilic addition of butene to sec $\left.-\mathrm{C}_{4} \mathrm{H}_{9}{ }^{+}\right) .{ }^{21}$ This indicated that oligomerization still proceeded stably when acidity centres were less in number and weaker. Therefore, the inhibiting effect of fewer acid centres on cracking was more distinct than for alkylation and addition reaction, ${ }^{21}$ so that the selectivity of $\mathrm{C12}+$ increased with time on stream when the catalyst began to undergo deactivation.

For electrophilic addition of butene, C12 directly derived from the trimerization of butene was the main component in C9-C12, and C9-C11 was scarcely included in the alkylate products. However, the reducing order of selectivity was C11 > $\mathrm{C} 10>\mathrm{C} 9>\mathrm{C} 12+$, as observed in Fig. 6, which was contrary to the viewpoint that higher hydrocarbon than C8 was simply formed by butene oligomerizing. ${ }^{14}$

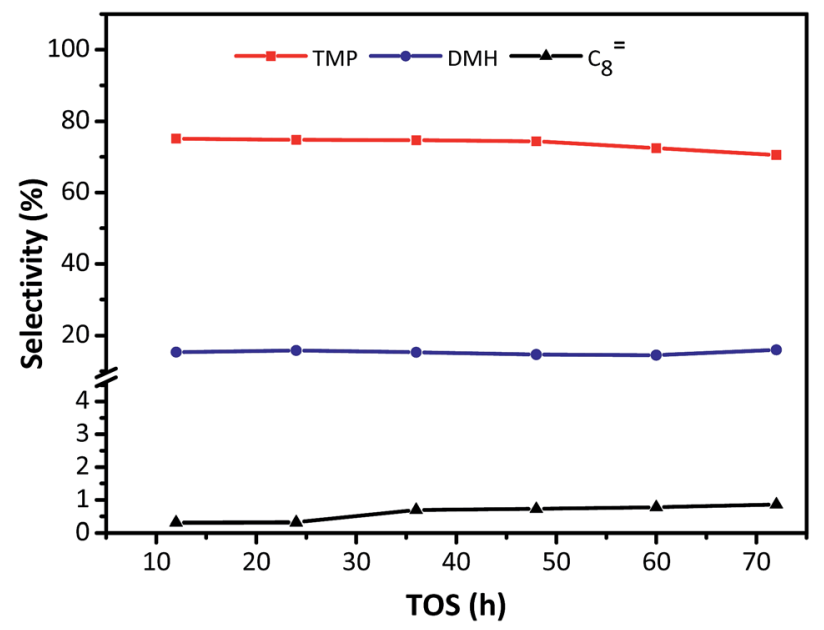

Fig. 7 Selectivity of individual C8 component in alkylate (C5+) vs. TOS over $\mathrm{HY}$ zeolites. Reaction condition: the ratio of isobutane to butene was $\mathrm{I} / \mathrm{O}=180, P=2.0 \mathrm{MPa}$, WHSV $=7.5 \mathrm{~h}^{-1}$.

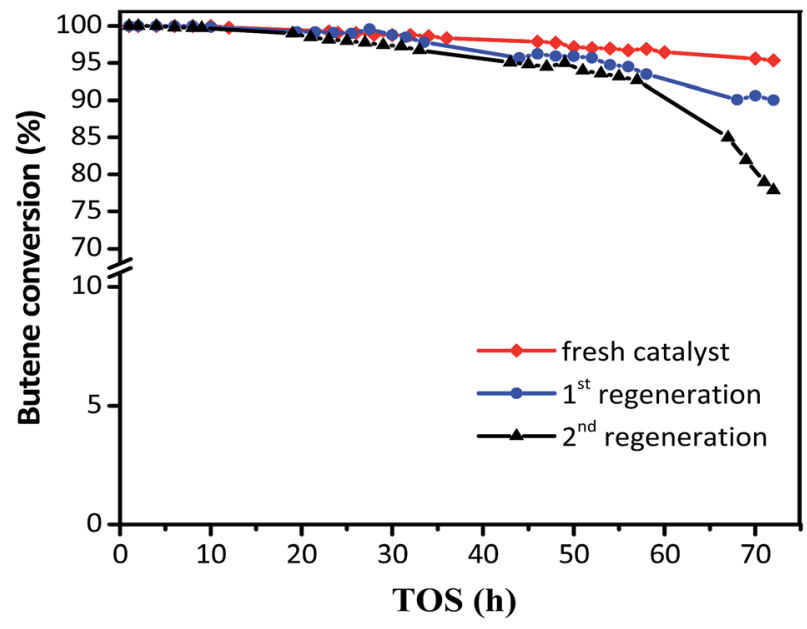

Fig. 8 Butene conversion with TOS in the presence of fresh and regenerated catalyst. Reaction condition: the ratio of isobutane to butene $(I / O=180), P=2.0 \mathrm{MPa}, \mathrm{WHSV}=7.5 \mathrm{~h}^{-1}$.

The regeneration effect is exhibited in Fig. 8, where the butene conversion recovered to $100 \%$ in the initial $10 \mathrm{~h}$ and then decreased at different gradients for the first and second regeneration. In addition, the product distribution (Table 3) showed that while the target TMP decreased from 72.51 to $69.36 \%$ for the first regeneration and $65.59 \%$ for the second regeneration, the selectivity of the alkylation byproducts increased, including those for $\mathrm{C} 5-\mathrm{C} 7$ and $\mathrm{C} 9+$. The initial butane conversion was $100 \%$ in $12 \mathrm{~h}$ for the regenerated catalysts, which was similar to that for the fresh catalysts, inferring that the regeneration process was efficient. However, the sharp descent gradient and unsatisfactory product distribution of spent catalysts after $15 \mathrm{~h}$ indicated that the stability of regenerated catalysts was inferior to that of the fresh samples, possibly because the coke could not be burned out completely. It can be considered that the used zeolites need to be regenerated once the butene conversion was lower than $100 \%$, which could avoid the formation of intractable carbon deposits and facilitate the recovery of the activity of the catalyst.

\subsection{Formation mechanism of alkylation byproducts}

It is clear that both cracking and oligomerization occurred in the process of butene alkylation (Fig. 9). Theoretically, the number of carbon atoms in primary oligomers originating from butene oligomerization is a multiple of four. However, $\beta$ -

Table 3 Products distribution of the fresh and used catalysts

\begin{tabular}{lccc}
\hline Catalysts & Fresh HY, \% & $1^{\text {st }}$ regeneration, \% & $2^{\text {nd }}$ regeneration, \% \\
\hline C5-C7 & 3.64 & 6.07 & 6.79 \\
C8 & 88.32 & 84.43 & 80.31 \\
TMP & 72.51 & 69.36 & 65.59 \\
DMH & 14.47 & 12.93 & 12.38 \\
C8 & 0.37 & 0.32 & 0.32 \\
C9+ & 8.05 & 9.51 & 12.90
\end{tabular}




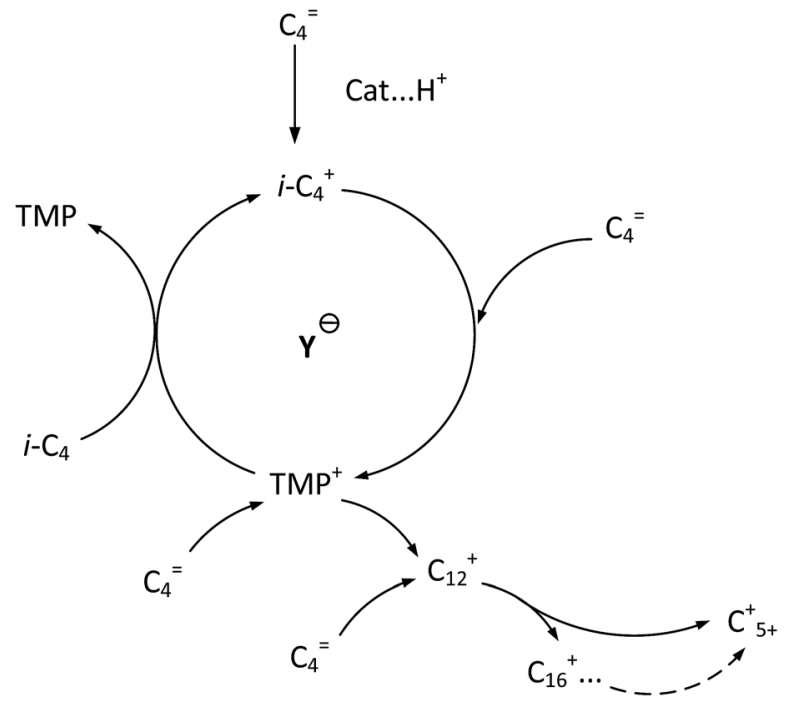

Fig. 9 Formation routes of target compound TMP and primary oligomers in isobutane/butene alkylation over zeolites. ${ }^{21,31}$

scission that can be easily initiated in longer chain hydrocarbons on acid sites, results in the carbon atom number of end products in alkylate oil ranging from 5 to 12. Cracking of C8 hardly took place in the alkylation conditions, supporting that C5-C7 components primarily stem from C12-C16. ${ }^{\mathbf{1 3 , 1 4}}$ Moreover, C9-C11 components were produced through two routes: (1) cracking of $\mathrm{C} 16+$ from tetramerization of butene ${ }^{13}$ and (2) electrophilic addition of C5-C7 carbocation with $\mathrm{C}_{4} \mathrm{H}_{8}$. Hence, the formation pathways of alkylation byproducts can be described as shown in Fig. 10.

As shown in Fig. 6, the selectivity of quantity of C5-C7 decreased gradually, but the selectivity of C9+ species increased with the deactivation of catalysts. The possible reason was that the acid strength of the catalyst was sufficient to promote hydride transfer and enable cracking at the initial stage of alkylation. ${ }^{32}$ Therefore, the cracking reaction rate, $r_{3}$, of $\mathrm{C} 12+$ remained high and the selectivity of $\mathrm{C} 5-\mathrm{C} 7$ hydrocarbons was

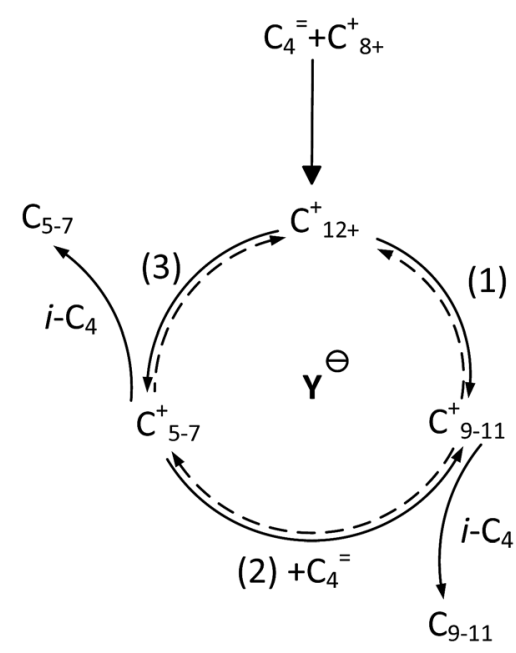

Fig. 10 Formation routes of alkylation byproducts.

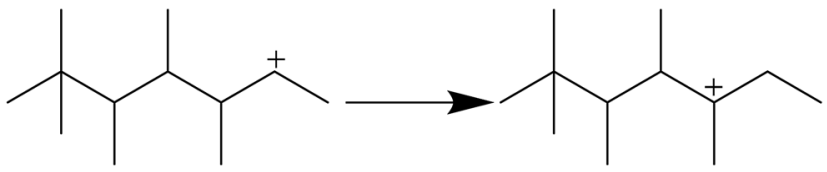

Scheme 1 Intramolecular hydride transfer.

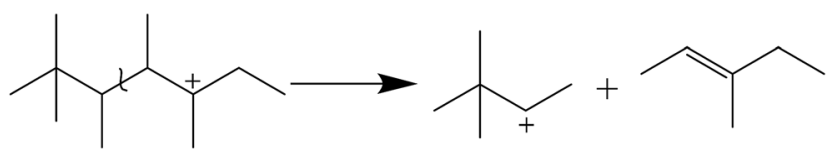

Scheme 2 Cracking of long chain carbocation.

maximum. Nevertheless, the decreased content and strength of acid centers with catalysts deactivation, particularly Brønsted acid centers, enhanced oligomers but suppressed cracking more drastically when compared to the addition of butene with carbonations. This was because stimulation of cracking required stronger acidity. ${ }^{20}$

As shown in Fig. 6, there are no C1-C3 hydrocarbons, indicating that extended cracking of primary crackates scarcely occurred in the alkylation process. As a result, crackates of $\mathrm{C12}+$ only included $\mathrm{C} 4-\mathrm{C} 8$, in which $\mathrm{C} 4$ and $\mathrm{C} 8$ were directly reversible reactants. Moreover, the existence of $\mathrm{C} 5-\mathrm{C} 7$ hydrocarbons indicated the possibility of hydride transfer in $\mathrm{C} 12+$ as shown in Scheme 1, where C12+ was the primary oligomer of 2-butene on HY zeolites.

In addition, the $\mathrm{C} 6$ species was generated via the cleavage of C-C bond as shown in Scheme 2. Similarly, C5 and C7 hydrocarbons were also formed by the $\beta$-scission of other $\mathrm{C} 12+$ isomers.

It is speculated that the higher the carbocation, the more carbon atoms are possessed by the primary products of cracking. Therefore, the selectivity of cracking products decreased in the following order: C7 > C6 > C5. Correspondingly, the selectivity decreasing in the order of C9-C11 can be explained based on two reasons: (1) the more alkyl groups in the carbocation chain, the faster the electrophilic addition rate because the products with more alkyl groups were more stable due to charge dispersion. (2) The higher the concentration of reactants, the easier the oligomerization reaction. It is necessary to emphasize that only $\mathrm{C} 12$ was detected in C12+ alkylate oil, possibly because chromatography function was limited and the higher carbon number components retained over catalysts. ${ }^{13}$ There was a greater potential for sequential addition of $\mathrm{C} 12+$ once it was formed via the addition of C8+ with butene, suggesting accumulation of $\mathrm{C} 12$ was few. Moreover, it was possible that $\mathrm{C} 12$ was converted into $\mathrm{C} 5-\mathrm{C} 7$. As a result, the selectivity of C9-C11 was higher than that of $\mathrm{C} 12$ though the relative rate of oligomerization increased.

\section{Conclusions}

Isobutane alkylation with butenes was carried out over synthesized HY zeolites in a tubular reactor. HY zeolites exhibited 
ideal activity and desirable selectivity of C8 hydrocarbon at $75{ }^{\circ} \mathrm{C}$ with a butane conversion rate above $95 \%$ and the selectivity of C8 near to $90 \%$. However, the deactivation of catalysts was unavoidable due to the decrease of surface area and acid sites concentration. The selectivity of C5-C7 decreased because of the weakened cracking ability, resulting from the decreased acid sites especially Brønsted acid sites. Moreover, the enhanced selectivity of C9-C11 was due to the addition of C5C7 carbocations with butane, which was another factor to decrease the accumulation of C5-C7. It is indispensable to further study the improvement measurements of particles dispersion and pores distribution of HY zeolites used in the alkylation of isobutane with butene.

\section{Conflicts of interest}

There are no conflicts to declare.

\section{Acknowledgements}

We thank the National Key Research and Development Plan (No. 2016YFC0303701), Beijing Novo Program Interdisciplinary Studies Cooperative project, Science Foundation of China University of Petroleum, Beijing (No. 2462014YJRC011, 201604) for the support.

\section{References}

1 A. Sarkar, D. Seth, F. T. T. Ng, et al., Ind. Eng. Chem. Res., 2014, 53, 18982-18992.

2 A. E. Koklin, V. M. K. Chan, V. B. Kazanskii, et al., Kinet. Catal., 2010, 51, 410-415.

3 R. Klingmann, R. Josl, Y. Traa, et al., Appl. Catal., A, 2005, 281, 215-223.

4 C. Sievers, J. R. S. Liebert, M. M. Stratmann, et al., Appl. Catal., A, 2008, 336, 89-100.

5 J. a. V. Bokhoven, A. L. Roest and D. C. Koningsberger, J. Phys. Chem. B, 2000, 104, 6743-6754.

6 L. Yuying, L. Yongxiang, L. Jun, et al., Acta Pet. Sin., 2014, 30, 765-771.

7 T. Juzsakova, A. Csavdari, A. Redey, et al., Environ. Eng. Manage. J., 2014, 13, 2343-2347.

8 B. O. D. Costa and C. A. Querini, Chem. Eng. J., 2010, 162, 829-835.
9 C. Sievers, I. Zuazo, A. Guzman, et al., J. Catal., 2007, 246, 315-324.

10 L. Patrylak, O. P. Pertko, S. V. Konovalov, et al., Curr. Catal., 2016, 5, 108-115.

11 K. I. Patrilyak, L. K. Patrilyak, Y. G. Voloshina, et al., Theor. Exp. Chem., 2011, 47, 205.

12 K. Yoo and P. G. Smirniotis, Appl. Catal., A, 2002, 227, 171179.

13 K. Yoo, E. C. Burckle and P. G. Smirniotis, J. Catal., 2002, 211, 6-18.

14 S. V. Nayak, P. A. Ramachandran and M. P. Dudukovic, Chem. Eng. Sci., 2010, 65, 335-342.

15 B. O. D. Costa and C. A. Querini, Appl. Catal., A, 2010, 385, 144-152.

16 A. C. Oliveira, N. Essayem, A. Tuel, et al., J. Mol. Catal. A: Chem., 2008, 293, 31-38.

17 K. Yoo and P. G. Smirniotis, Appl. Catal., A, 2003, 246, 243251.

18 A. Corma, A. Martínez and C. Martínez, J. Catal., 1994, 146, 185-192.

19 Z. Qin, K. A. Cychosz, G. Melinte, et al., J. Am. Chem. Soc., 2017, 139, 17273-17276.

20 C. A. Querinl and E. Roa, Appl. Catal., A, 1997, 163, 199-215. 21 A. Feller, J. Catal., 2003, 220, 192-206.

22 A. Feller, I. Zuazo, A. Guzman, et al., J. Catal., 2003, 216, 313323.

23 L. K. Patrilyak and P. I. Bartosh, Theor. Exp. Chem., 2003, 39, 177-183.

24 L. K. Patrylak and I. A. Repetskyi, Theor. Exp. Chem., 2013, 49, 143-157.

25 H. Yigong and H. Yufeng, Chin. J. Catal., 2000, 21, 175-178.

26 H. J. Lee, D.-C. Kang, S. H. Pyen, et al., Appl. Catal., A, 2017, 531, 13-20.

27 L. b. Qin, J. Han, Y. Q. Zhan, et al., Energy Fuels, 2016, 30, 544-550.

28 L. b. Qin, J. Han, W. Y. Chen, et al., Appl. Therm. Eng., 2016, 94, 813-818.

29 C. A. Emeis, J. Catal., 1993, 141, 347-354.

30 D. H. Park, S.-S. Kim, T. J. Pinnavaia, et al., J. Phys. Chem. C, 2011, 115, 5809-5816.

31 R. Nilton Jr and A. C. J. Mota, J. Braz. Chem. Soc., 2005, 16, 691-694.

32 W. Xinxing, Q. Xiaolei, S. Jingming, et al., Ind. Catal., 2017, 25, 61-65. 